\title{
Tissue-engineered cartilage and bone using stem cells from human infrapatellar fat pads
}

\author{
J. L. Dragoo, B. Samimi, M. Zhu, S. L. Hame, B. J. Thomas, J. R. Lieberman, \\ M. H. Hedrick, P. Benhaim \\ From the UCLA Medical Centre, Los Angeles, USA
}

M ultipotential processed lipoaspirate (PLA) cells extracted from five human infrapatellar fat pads and embedded into fibrin glue nodules, were induced into the chondrogenic phenotype using chondrogenic media. The remaining cells were placed in osteogenic media and were transfected with an adenovirus carrying the cDNA for bone morphogenetic protein-2 (BMP-2). We evaluated the tissue-engineered cartilage and bone using in vitro techniques and by placing cells into the hind legs of five severe combined immunodeficient mice.

After six weeks, radiological and histological analysis indicated that the PLA cells induced into the chondrogenic phenotype had the histological appearance of hyaline cartilage. Cells transfected with the $B M P$-2 gene media produced abundant bone, which was beginning to establish a marrow cavity. Tissueengineered cartilage and bone from infrapatellar fat pads may prove to be useful for the treatment of osteochondral defects.

J Bone Joint Surg [Br] 2003;85-B:740-7.

Received 28 May 2002; Accepted after revision 14 August 2002

Defects of the articular surface are among the most disabling of all orthopaedic injuries. Many methods of treatment have been used to decrease pain and improve the level of

J. L. Dragoo, MD, Resident

S. L. Hame, MD, Assistant Professor

B. J. Thomas, MD, Clinical Professor

J. R. Lieberman, MD, Associate Professor

P. Benhaim, MD, Associate Professor

Department of Orthopaedic Surgery

B. Samimi, BS, Medical Student

M. Zhu, MS, Research Director

Laboratory for Regenerative Bioengineering and Repair, Department of Surgery

M. H. Hedrick, MD, Assistant Professor

Department of Plastic Surgery

UCLA Medical Centre, 200 UCLA Medical Plaza, Suite 140, Los Angeles, California 90095-6092, USA.

Correspondence should be sent to Dr J. L. Dragoo.

C 2003 British Editorial Society of Bone and Joint Surgery

doi:10.1302/0301-620X.85B5.13587\$2.00 function of affected individuals. ${ }^{1-16}$ These procedures, however, have numerous shortcomings such as the formation of fibrocartilaginous repair tissue, which lacks the mechanical properties of normal articular cartilage, limited tissue availability, donor-site morbidity with autografts, the possibility of transmission of disease, and handling difficulties with allografts. Consequently, recent research has focused on laboratory-engineered osteochondral tissue.

Cao et $\mathrm{al}^{17}$ and Vacanti et al ${ }^{18}$ have had success producing hyaline-like tissue from bovine chondrocytes using polylactic-polyglycolic acid matrices. The use of both autogenous and allograft chondrocytes in tissue engineering is problematical because of a relatively small cellular yield at harvest, thereby necessitating long culture expansion. Bruder et $\mathrm{al}^{19}$ engineered bone and cartilage using mesenchymal stem cells derived from bone marrow. This technique is an appealing option, but harvesting of bone marrow is painful and yields a limited number of stem cells, again making culture expansion necessary, especially in the elderly.

Human liposuction aspirates contain multipotential cells, termed processed lipoaspirate cells. ${ }^{20}$ Isolation of singlecell populations (clones) of PLA cells has shown that they have at least a trilineage potential to form bone, cartilage, and fat. Compared with cells harvested by bone-marrow aspiration, PLA cells are easier to obtain, have a lower donor-site morbidity, and are available in larger numbers. Obtaining large numbers of stem cells at harvest eliminates the need for costly and lengthy tissue-culture expansion, which would subject the patient to a staged second procedure to reimplant the induced cells.

Liposuction is a technique which is unfamiliar to most orthopaedic surgeons. They may, however, resect infrapatellar fat pads during total knee arthroplasty, with minimal morbidity, for improved surgical visualisation and to prevent possible impingement of the fat by the prosthesis. Fat pads are also safely resected arthroscopically in patients with chronic impingement and fibrosis of the fat pad (Hoffa's disease). ${ }^{21,22}$ In the study by Ogilvie-Harris and Giddens, ${ }^{22}$ these patients experienced significant improvement in function and symptoms using standardised knee scores at a mean follow-up of 76 months. Although the consequences of resection of the infrapatellar fat pad in young, healthy individuals has not been studied, it is unlikely to 
worsen the symptoms or function of a patient already hampered by a significant osteochondral defect. If fat pads can be removed without adversely affecting the patient, they would provide a relatively large source of adipose tissue (PLA cells).

Our aim therefore was to determine: 1) if infrapatellar fat pads contain sufficient quantities of PLA cells for application in tissue engineering; 2) if the extracted PLA cells have the potential for induction into the chondrogenic and osteogenic phenotypes; and 3) if cartilage and bone are produced after implantation of these cells in an animal model. We also devised a technique for arthroscopic harvest of infrapatellar fat pads for application in tissue engineering.

\section{Patients and Methods}

Cell harvest. After informed consent and approval from the Human Research Subject Committee, we harvested five viable infrapatellar fat pads during routine total knee arthroplasty and calculated the volume of each. The mean age of the patients was 74 years (53 to 86).

Extraction of stem cells. PLA cells were extracted from the fat pads using a previously published protocol. ${ }^{20}$ Briefly, the fat underwent a series of washes with phosphate-buffered saline, was digested with $0.05 \%$ collagenase (Sigma, $\mathrm{St}$ Louis, Missouri) at $37^{\circ} \mathrm{C}$ and shaken at $165 \mathrm{rpm}$ for $30 \mathrm{~min}-$ utes to separate the mature adipocytes from the PLA cells. After neutralisation of the collagenase with $10 \%$ fetal bovine serum (FBS; Tissue Culture Biologics, Tulare, California), the solution was centrifuged at $250 \mathrm{~g}$ for ten minutes. We discarded the supernatant with all the mature adipocytes and resuspended the resultant cellular fraction containing PLAs in Dulbecco's modified Eagle's medium with 10\% FBS (DMEM-10; Cellgro, Herndon, Virginia). The cellular yield was calculated using a haemacytometer and cell viability was checked using Trypan Blue exclusion dye. Even though sufficient cells were harvested to provide cartilage and bone for a moderately-sized clinical defect, they were cultured and expanded (passage two) to allow for multiple analyses.

Induction of cartilage. After the PLA cells had been harvested and resuspended in DMEM-10, micromasses of cartilage were created by plating $15 \mu \mathrm{l}$ of $1.5 \times 10^{7}$ cells $/ \mathrm{cm}^{3}$ into each of 48 wells. After incubation for one hour, $200 \mathrm{ml}$ of chondrogenic media consisting of DMEM, 10\% FBS, $100 \mathrm{ng} / \mathrm{ml}$ of insulin growth factor- $1,5 \mathrm{ng} / \mathrm{ml}$ of fibroblast growth factor-2, $10 \mathrm{ng} / \mathrm{ml}$ of growth hormone, $50 \mu \mathrm{g} / \mathrm{ml}$ of ascorbic acid-2-phosphate and $6.25 \mu \mathrm{g} / \mathrm{ml}$ of transferrin were added to each well. Nodules were harvested after being cultured at $37^{\circ} \mathrm{C}$ for one week and broken apart with collagenase and centrifugation. Fibrin glue was added and 30 minutes after clot formation the nodules were incubated with the chondrogenic media at $37^{\circ} \mathrm{C}$ with $5 \% \mathrm{CO}_{2}$ for three weeks. The nodules were centrifuged daily at $700 \mathrm{~g}$ for five minutes in order to subject them to forces similar to those generated in the intra-articular environment.
Induction of bone. For induction of the PLA cells to the osteogenic phenotype we used an osteogenic media consisting of DMEM-10 supplemented with $50 \mu \mathrm{M}$ of ascorbic acid-2-phosphate and $10 \mathrm{mM}$ of beta-glycerol phosphate, along with bone morphogenetic protein-2 (BMP-2) as the osteoinductive signal protein. Using a previously published protocol we developed a recombinant adenovirus with the gene for BMP-2 (Ad-BMP-2) by inserting the cDNA for recombinant human $B M P-2$ (rhBMP-2) into the plasmid vector pAC-cytomegalovirus. ${ }^{23}$

When cultured cells reached $90 \%$ confluence, PLA cells were infected by adding the virus at a multiplicity of infection of 100 . The plates were incubated at $37^{\circ} \mathrm{C}$ for 24 hours. Analysis of the supernatant using the Western blot technique for identification of BMP-2 denoted viral transduction. Transduced cells were then cultured for an additional week.

\section{Analysis of cartilage}

Histochemical staining. After the nodules had been fixed in paraformaldehyde and embedded in paraffin, $6 \mu \mathrm{m} \mathrm{sec-}$ tions were cut, mounted on slides and stained using standard haematoxylin and eosin and Alcian Blue protocols. Digital images were obtained using a Zeiss Axioskop II microscope (Carl Zeiss, Munich, Germany) and Spot software (Diagnostic Instruments Inc, Sterling Heights, Michigan).

Production of glycosaminoglycan. The concentration of glycosaminoglycan in the cartilaginous matrices was measured spectrophotometrically using a modified dimethylmethylene blue protocol. ${ }^{24}$ After digestion of the nodules in sodium phosphate buffer ( $\mathrm{pH}$ 6.8) containing $1 \mathrm{mM}$ EDTA, $2 \mathrm{mM}$ dithiothreitol and $300 \mu \mathrm{g}$ of papain at $60^{\circ} \mathrm{C}$ for 60 minutes the samples were analysed by spectrophotometry using a dimethylmethylene blue colour reagent at $A_{525}$.

RNA/gene expression by reverse transcriptase-polymerase chain reaction (RT-PCR). Tissue was harvested at confluency and total RNA prepared using the RNAase kit, following the standard protocol provided by the manufacturer (Qiagen, Valencia, California). For oligo dT-primed cDNA synthesis we used MMLV-reverse transcriptase (Promega). Briefly, total RNA was denatured at $70^{\circ} \mathrm{C}$ for five minutes, snap cooled on ice and then incubated with dNTP and MMLV-RT for a minimum of two hours at $42^{\circ} \mathrm{C}$. For PCR amplification of the cDNA we used primer pairs designed to the following genes: $(F=$ forward oligo, $R=$ reverse oligo)

a) Human type II collagen $\alpha 1$

(expected product size: $328 \mathrm{bp}$ )

$\mathrm{F}=$ 5'-CCA AGT ACT TTC CAA TCT CAG TCA C-3'

$\mathrm{R}=5^{\prime}$-ACA GAA TAG CAC CAT TGT GTA GGA C-3'

b) Aggrecan (expected product size: $500 \mathrm{bp}$ )

$\mathrm{F}=5^{\prime}$-GCG ATA TCA TGA CCA CTT TAC TC-3'

$\mathrm{R}=5$ '-CCT GTC AAA GTC GAG GGT GT-3'

c) Human type-X collagen (expected product size: 600 bp) 


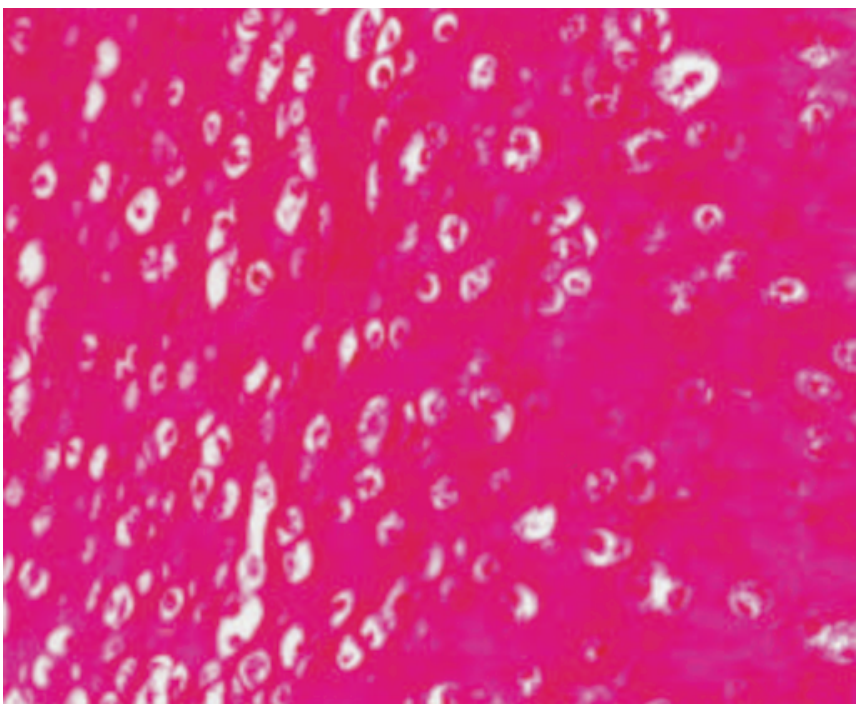

Fig. 1a

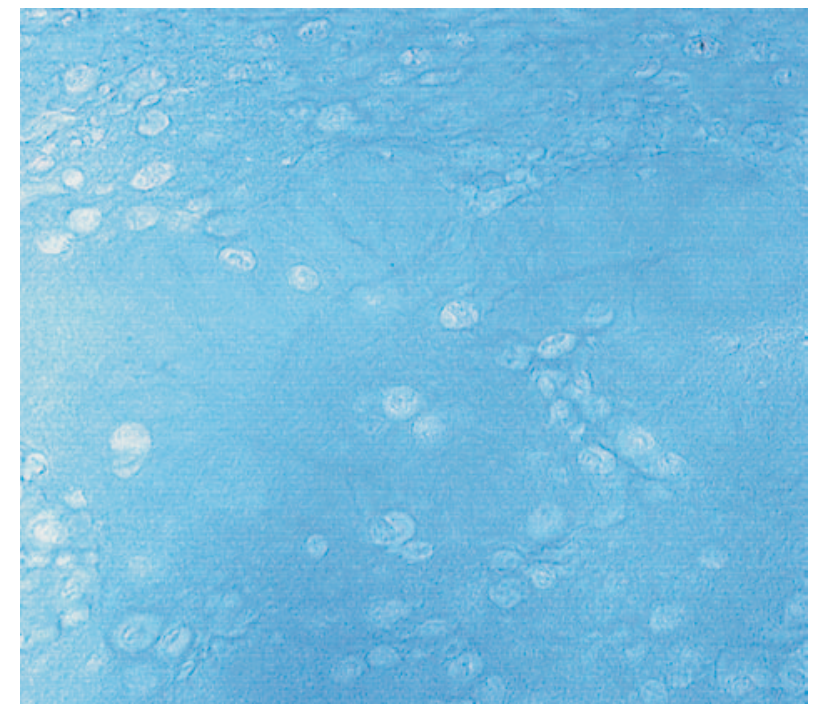

Fig. 1b

Photomicrographs showing that in vitro chondrogenic induction of PLA cells resulted in transitory fibrohyaline cartilage at three weeks (a) haematoxylin and eosin and b) Alcian Blue at $\mathrm{pH} 1$ x 400).

$\mathrm{F}=$ 5' -TGG AGT GGG AAA AAG AGG TG-3'

$\mathrm{R}=$ 5'-GTC CTC CAA CTC CAG GAT CA-3'

The samples underwent protein denaturation at $95^{\circ} \mathrm{C}$ for one minute, annealling at $53^{\circ} \mathrm{C}$ for one minute, extension at $72^{\circ} \mathrm{C}$ for one minute, then PCR amplification for 35 cycles, and a final incubation at $72^{\circ} \mathrm{C}$ for five minutes. The optimal annealling temperature for each primer pair was calculated using OLIGO primer analysis software. PCR using primers to $\beta$-actin was used as a positive control. PCR products were resolved using conventional agarose gel electrophoresis.

In vivo severe combined immunodeficient (SCID) mouse assay. After approval from the Animal Research Committee, PLA cell and fibrin glue nodules were implanted into the hind legs of five SCID mice (UCLA Defined Flora Colony, male, 4-week mice). After anaesthetising, shaving and preparing the mice, an incision was made bilaterally on the lateral aspect of the femur. The subcutaneous tissues and fascia lata were incised sharply. Dissecting scissors were used to define a plane between vastus lateralis and biceps femoris. The PLA cell and fibrin glue nodules were implanted in this muscular interval, which was then closed with 4-0 nylon sutures. Fibrin glue nodules without stem cells were implanted in the same manner in the contralateral limb as a negative control.

At six weeks, the animals were sacrificed and evaluated radiologically to ensure that there was no formation of bone. The implants were then removed, processed, embedded in paraffin, sectioned $(6 \mu \mathrm{m})$, and stained with haematoxylin and eosin and Alcian Blue.

\section{Analysis of bone}

Histochemical staining. After transfection and induction in osteogenic media, cells were stained for alkaline phos- phatase activity using Fast Red TR salt (Sigma) and AS-BI phosphate (Sigma) dissolved in dimethyl sulphoxide. Positive activity of alkaline phosphatase was detected as a red stain. The specimens were digitally photographed using the Zeiss Axioskop II microscope.

Before assessment of matrix calcification selected plates were stained with Trypan Blue to verify cell viability. The von Kossa protocol using silver nitrate and exposure to ultraviolet light detected calcification as a black stain. After counterstaining with Eosin (Sigma) the specimens were digitally photographed using the Zeiss Axioskop II microscope. RNA/gene expression by RT-PCR. Preparation of the RNA was as for the analysis of cartilage. PCR amplification of the cDNA for bone precursor proteins was executed using primer pairs designed to the following genes: $(\mathrm{F}=$ forward oligo, $\mathrm{R}=$ reverse oligo)

a) Type-I collagen (expected product size: $598 \mathrm{bp}$ )

F = 5'-CAT CTC CCC TTC GTT TTT GA-3'

$\mathrm{R}=$ 5' - CTG TGG AGG AGG GTT TCA GA-3'

b) Core binding factor-1 (expected product size: $320 \mathrm{bp}$ )

$\mathrm{F}=$ 5'-CTC ACT ACC ACA CCT ACC TG-3'

$\mathrm{R}=$ 5' -TCA ATA TGG TCG CCA AAC AGA TTC-3'

c) bone sialoprotein (expected product size: $185 \mathrm{bp}$ )

$\mathrm{F}=$ 5'-GCT CTA GAA TGA AGA CTG CTT TAA TT-3'

R = 5'-CGG GAT CCT CAC TGG TGG TGG TAG-3'

In vivo SCID mouse assay. PLA cells transduced with the BMP-2 gene (PLA-Ad-BMP-2) were seeded on to collagenI sponges and implanted into the hind-legs of five SCID mice (UCLA Defined Flora Colony, male, 4-week mice) as for analysis of cartilage. 
Chondrogenic precursors

$$
\begin{aligned}
& \text { Collagen type II } \\
& \text { Aggrecan } \\
& \text { Collagen type } X
\end{aligned}
$$

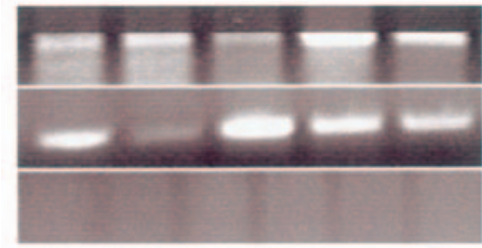

Osteogenic precursors

Core Binding Factor-1 (Cbfa-1)

Bone Sialoprotein
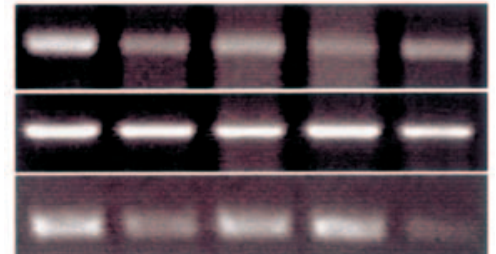

Fig. 2

RT-PCR analysis of cartilage at three weeks (chondrogenic procursors) and bone at one week (osteogenic procursors).
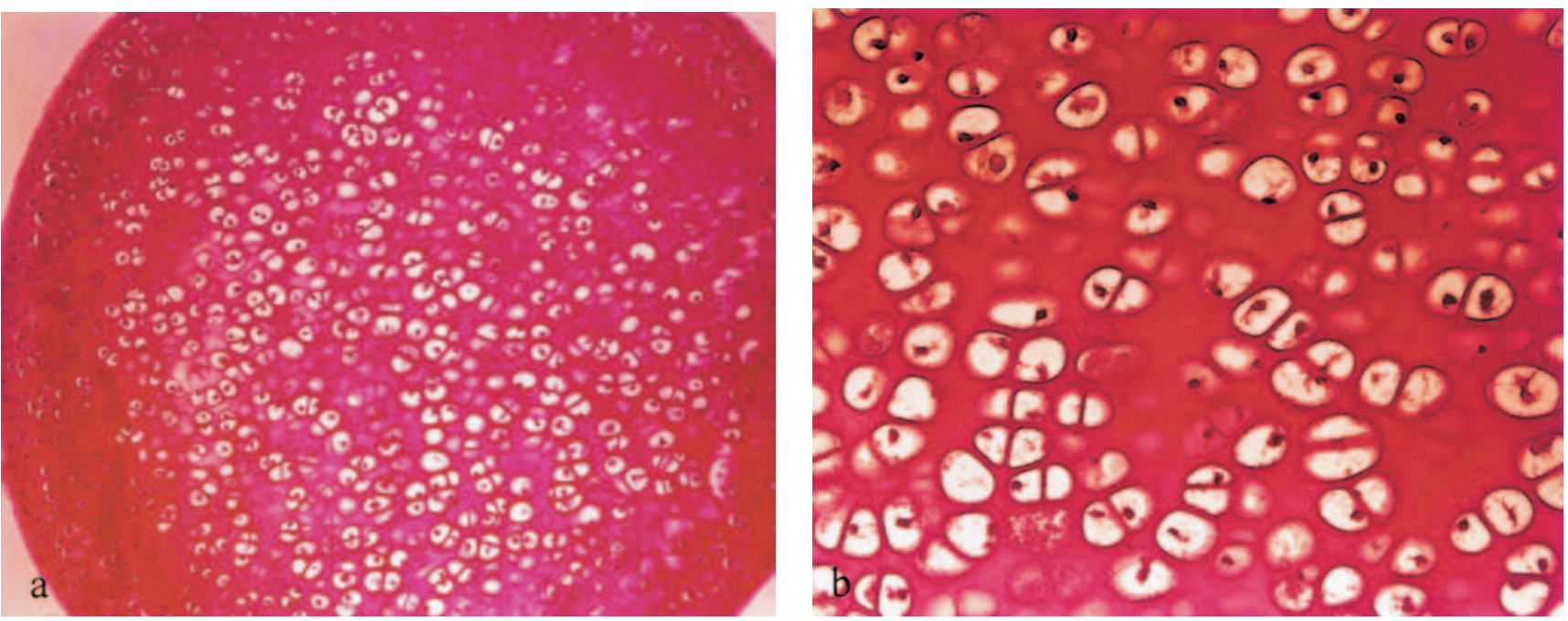

Fig. 3

Photomicrographs showing that in vivo chondrogenic induction of PLA cells in SCID mice resulted in hyaline cartilage at six weeks (haematoxylin and eosin: a) low power and b) high power ( $\mathrm{x} 400$ ).

\section{Results}

All five human fat pads were harvested successfully without injury to the underlying patellar ligament. At follow-up at six months there were no complications or symptoms beyond the expected postoperative pain associated with total knee arthroplasty.

The mean volume of fat per resected fat pad was $20.6 \mathrm{ml}$ (15 to 25 ), which yielded a mean of $5.5 \times 10^{6}$ extracted cells/fat pad $\left(2.0 \times 10^{6}\right.$ to $\left.1.2 \times 10^{7}\right)$. Cells appeared to be healthy after extraction and had a doubling time of 50 to 60 hours.

Induction of cartilage. Nodules of cells induced into the cartilage phenotype in vitro had a white, glistening macroscopic appearance at one week. All nodules grew in size substantially over the next two weeks. At harvesting at three weeks, the nodules were rubbery in consistency with a uniformly semitransparent white colour. Staining with haematoxylin and eosin of all nodules revealed cells contained within lacunae surrounded by abundant gel-like extracellular matrix (ECM) with a few visible collagen fibres (Fig. 1a). The histological appearance was consistent with fibrohyaline cartilage. The mesenchyme surrounding the cartilaginous tissue condensed to form a fibrous layer, similar to perichondrium.

Staining with Alcian Blue was positive in all nodules (Fig. 1b). RT-PCR analysis confirmed the presence of typeII collagen and aggrecan in all nodules (Fig. 2). Type-X collagen, which indicates regressive change into hypertrophic cartilage, was not present in any specimen. The product of 

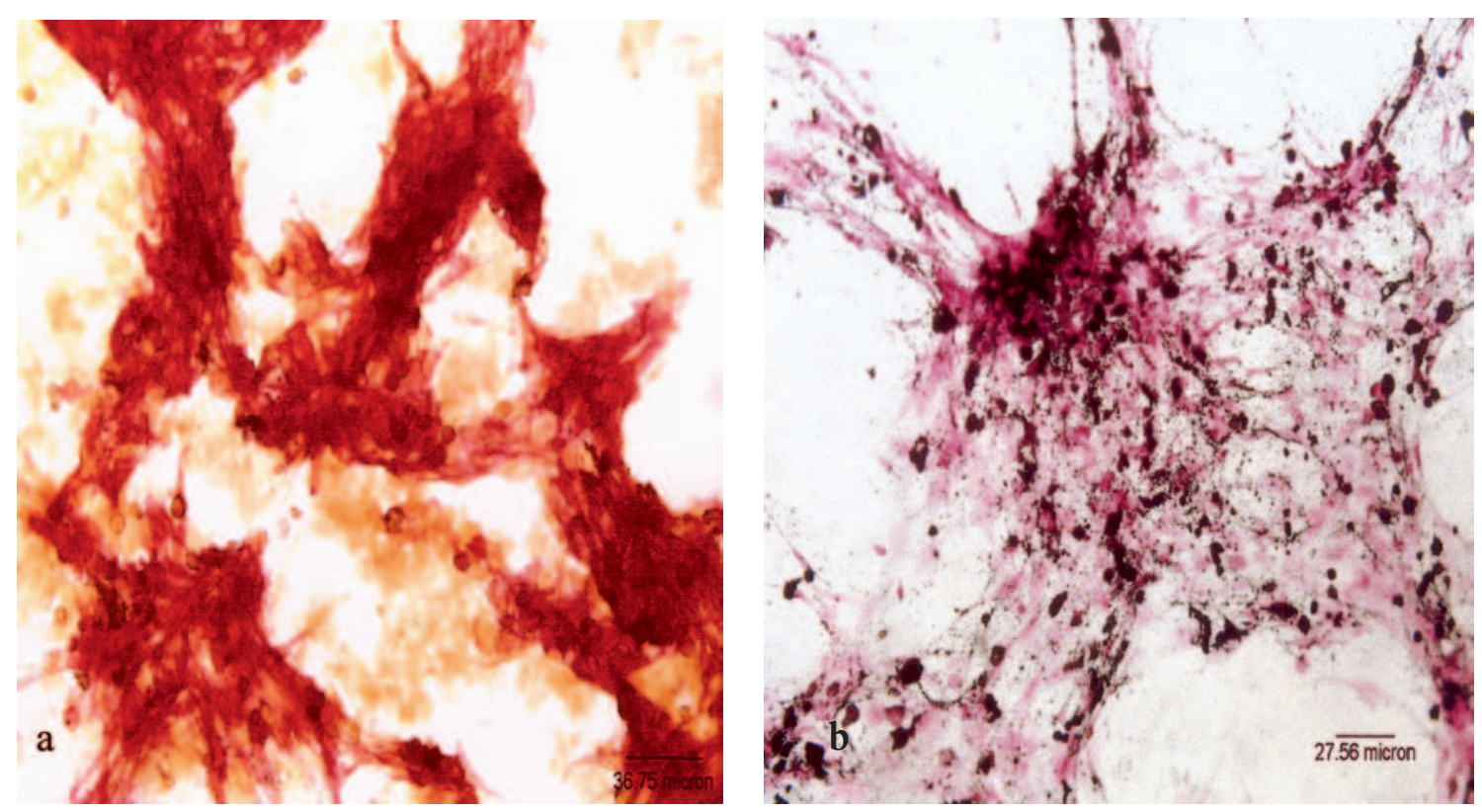

Fig. 4

Photomicrographs showing in vitro bone induction of BMP-2 transduced PLA cells in culture at one week (a) staining for alkaline phosphatase and b) von Kossa staining for matrix calcification x 80).

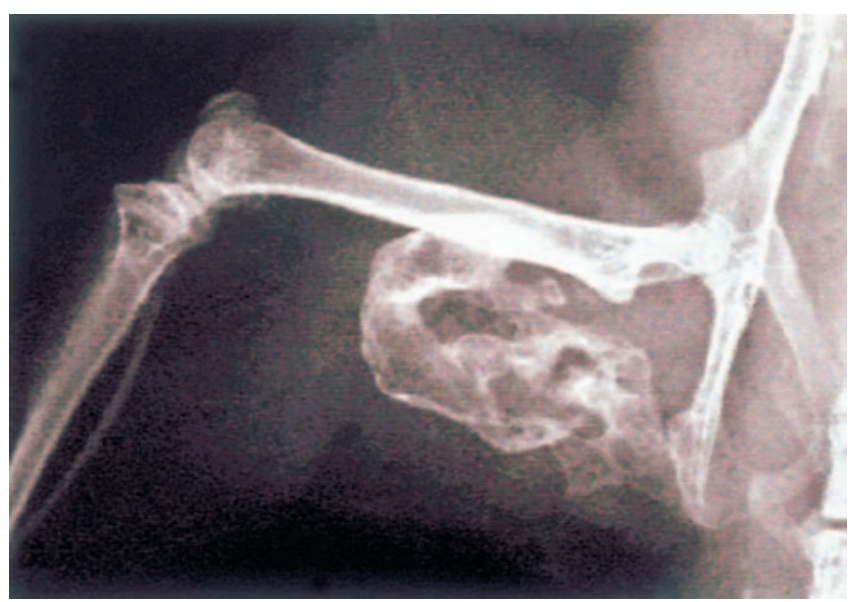

Fig. 5a

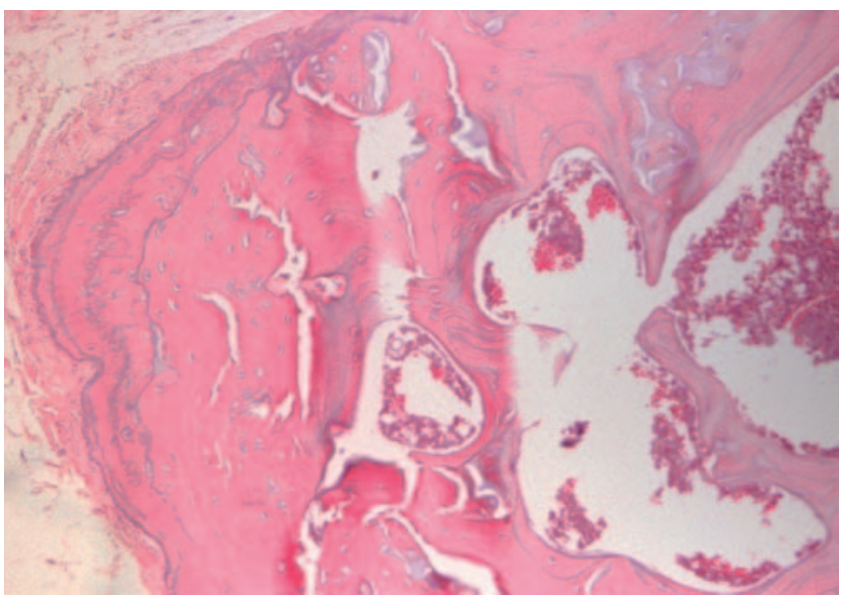

Fig. $5 b$

In vivo bone induction of BMP-2 transduced PLA cells in SCID mice at six weeks. Figure 5a - Radiograph of the implant. Figure 5b - Haematoxylin and eosin staining of a section through the implant showing adequately mineralised bone, which is beginning to establish a marrow cavity (x 80).

PCR positive controls was of proper base pair size, while negative controls remained negative (data not shown). The mean concentration of glycosaminoglycan in tissue-engineered nodules was $23 \mu \mathrm{g}$ (18.2 to 26.3 ) compared with 46 $\mu \mathrm{g}$ in a sample of human articular cartilage of similar size.

In vivo implantation of PLA cell/fibrin glue nodules in SCID mice produced histological cartilage at six weeks in all samples. The size of the nodule was considerably smaller at harvest compared with that at implantation. The nodules had a firm consistency and a uniformly semitransparent bluish-opal colour. Haematoxylin and eosin stained sections of all nodules showed increased organisation of the gel-like ECM without visible collagen fibres, which was consistent with hyaline cartilage (Fig. 3). All in vivo nodules stained positive for Alcian Blue at $\mathrm{pH}$ 1. Radiological analysis was negative for bone in all specimens.

Induction of bone. Cells induced into the osteogenic phenotype, in vitro, stained heavily for alkaline phos- 
phatase (Fig. 4a) and produced abundant extracellular matrix calcification (von Kossa stain) at one week (Fig. $4 \mathrm{~b})$. There was no appreciable cellular necrosis in any culture at the time of von Kossa staining. RT-PCR analysis confirmed the presence of type-I collagen, core binding factor-1, and bone sialoprotein at one week (Fig. 2). The product of PCR-positive controls was of proper base pair size, while negative controls remained negative (data not shown).

In vivo implantation of PLA-Ad-BMP-2 cells on collagen type-I sponges in SCID mice produced abundant radiologically evident bone at six weeks in all specimens (Fig. 5a). Histological examination showed bone which was beginning to remodel and establish a marrow cavity (Fig. 5b). Control legs implanted with non-transduced PLA cells on collagen type-I scaffolds failed to produce any evidence of bone, either radiologically or histologically at six weeks.

\section{Discussion}

With recent advances in tissue-engineering techniques, the use of stem cells to produce cartilage and bone tissue may soon be a viable therapeutic option for the treatment of osteochondral defects. Harvesting of stem cells from fat reduces donor-site morbidity associated with harvesting of autogenous chondrocytes or bone marrow and yields a comparatively large volume of cells. By contrast, culture expansion after bone-marrow harvest is lengthy, costly, and requires a second staged procedure for reimplantation of the induced cells.

Previously published studies have shown the multipotent nature of stem cells derived from human fat. ${ }^{20}$ Adipose tissue is readily available to the orthopaedic surgeon, either by subcutaneous fat resection or by resection of the infrapatellar fat pad. PLA cells from infrapatellar fat pads can be harvested in larger numbers compared with alternate stem-cell sources such as bone marrow and muscle. Previous studies have shown that a bone-marrow aspirate of $30 \mathrm{ml}$ produces approximately $1 \times 10^{5}$ cells, while a liposuction aspirate yields approximately $3.3 \times 10^{6}$ cells/ $100 \mathrm{~cm}^{3}$ of fat. ${ }^{25}$ In our study, the mean cell yield from one infrapatellar fat pad (mean volume $21 \mathrm{ml}^{3}$ ) was $5.5 \mathrm{x}$ $10^{6}$ cells. Although we cannot confirm that all harvested cells were stem cells, the technique used ensured that no bone or cartilage contaminated the fat specimens. The extracted cells were quickly and easily induced into cartilage and bone, producing engineered tissue both in vitro and in vivo. This technique of stem-cell harvest and induction would allow engineering of bone and cartilage composite grafts, which could treat deficiencies in the underlying subchondral bone as well as the articular surface.

In the laboratory, PLA cells were easily induced into the chondrogenic phenotype using the micromass technique, in which cells condense, withdraw their cellular processes, and form dense aggregates called protochondral tissue. Subsequently, signalling proteins (chondrogenic media) and environmental cues (centrifugal force to simulate weightbearing) cause the cells to produce metachromatic extracellular matrix. ${ }^{26}$ Induction of cartilage in harvested specimens was confirmed by: 1) the appearance of the gross specimens which have a homogenous, semitransparent bluish-opal colour and a rubbery consistency; 2) cells within lacunae surrounded by a gel-like matrix confirmed histologically; 3) staining with Alcian Blue at $\mathrm{pH} 1$ which is specific for highly sulphated proteoglycans characteristic of cartilaginous ECM; 4) the presence of the principal constituents of cartilage ECM, namely type-II collagen, aggrecan, and glycosaminoglycans; and 5) no evidence of regressive change of the cartilage (collagen type-X) into the osteogenic phenotype.

The in vitro cartilage nodules, harvested at three weeks, produced abundant ECM with a few visible collagen fibres. This is not consistent with fibrocartilage, which typically consists of chondrocytes with inconspicuous ECM found among abundant fibrous elements, often displacing cells into rows between fibre bundles. ${ }^{27}$ The presence of abundant ECM with minimal fibrous stranding in our in vitro nodules makes them most accurately classified as fibrohyaline cartilage, which is a transitional phase of cartilage generation. With time in vivo, however, these fibrohyaline cartilage nodules showed organised, homogeneous, gel-like ECM without any visible fibre network, which was consistent with the formation of hyaline cartilage. It appears that the additional environmental cues and biochemical influences within the animal model were necessary for further maturation towards hyaline cartilage.

Transduced PLA cells implanted in SCID mice were also induced towards the osteogenic phenotype in order to verify the bone-producing potential of stem cells extracted from human fat pads. At six weeks, all harvested specimens showed radiological and histological evidence of bone. Although non-transduced PLA cells produce bone precursor proteins when only ascorbate and inorganic phosphate are used for induction, PLA cells require culture with rhBMP-2 or transduction with the $B M P-2$ gene in order for formation of bone to occur in a clinically useful time frame. The osteoinductive properties of $B M P-2$ directly promote commitment of progenitor cells towards osteogenesis and produce a greater amount of matrix calcification in comparison with the addition of ascorbic acid-2-phosphate and $\beta$-glycerol phosphate alone. ${ }^{28}$

While the laboratory data clearly show the efficacy of this tissue-engineering technique, the clinical sequelae of harvesting infrapatellar fat pads is unknown. Resection of fat pads is well tolerated in patients undergoing total knee arthroplasty and from those with chronic fat pad impingement and fibrosis (Hoffa's disease). ${ }^{21,22}$ Partial resection is often undertaken during routine knee arthroscopy, without sequelae, for improved visualisation. Clearly, direct extrapolation of these results to young, active patients is not possi- 

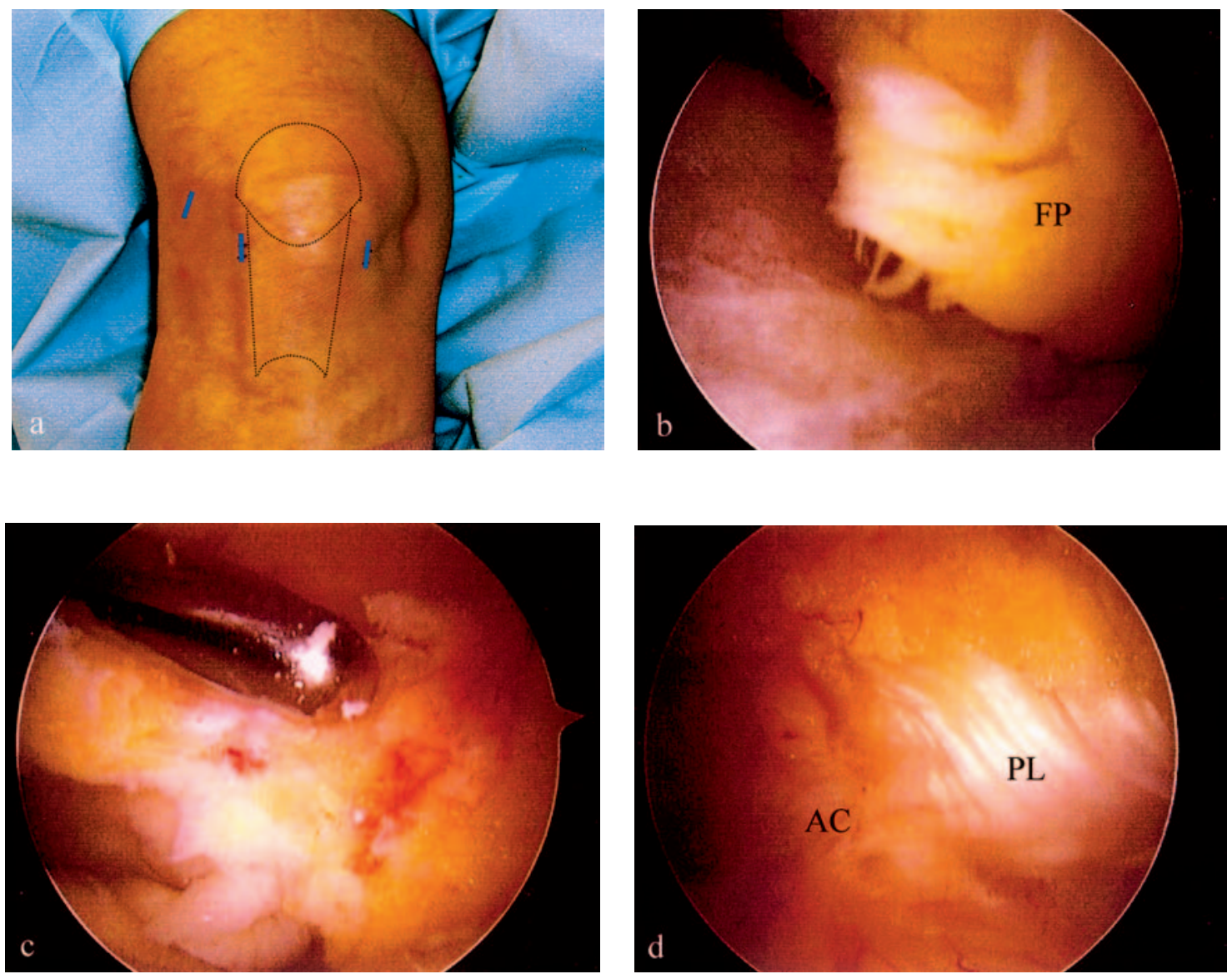

Fig. 6

Arthroscopic harvest of the infrapatellar fat pad showing a) the portal sites (blue) for fat pad resection, b) the view from the modified lateral midpatellar portal showing the fat pad (FP), c) the resection of the fat pad with a $5.5 \mathrm{~mm}$ full-radius shaver from the anteromedial portal, and d) horizontal fibres of the anterior capsular layer (AC) and underlying patellar ligament (PL).

ble, but those with osteochondral defects would be likely to experience significant relief from pain with repair of the articular surface.

We have explored arthroscopic resection of infrapatellar fat pads in patients requiring extensive debridement, and have determined that they can be safely removed if the anterior capsular layer is not breeched. This technique uses a modified lateral midpatellar portal (Fig. 6a), which allows visualisation of the entire fat pad (Fig. 6b). A $5.5 \mathrm{~mm}$ fullradius shaver is introduced through both anteromedial and anterolateral portals for excision of the fat (Fig. 6c). The anterior capsular layer is visualised, but is not breeched in order to protect the underlying patellar ligament (Fig. 6d). A thin layer of fat pad is left behind to decrease further the risk of damage to the patellar ligament.

In summary, human infrapatellar fat pads contain multipotential PLA cells which can be successfully harvested. This technique yields a large number of cells which can be rapidly induced into cartilage and bone to produce clinically useful amounts of tissue in a timely manner, eliminating the need for lengthy culture expan- sion. Therefore, the fat pad may be an ideal source of mesenchyme-lineage stem cells for tissue-engineering strategies which orthopaedic surgeons could use to repair debilitating osteochondral defects. Other studies are currently under way using animal models to examine the therapeutic benefits of these cells to repair articular surface and bony defects.

The authors wish to thank J. Choi, MD, P. A. Zuk, PhD, and K. A. Nielsen, MD for their contributions to this manuscript.

No benefits in any form have been received or will be received from a commercial party related directly or indirectly to the subject of this article.

\section{References}

1. Johnson LL. Arthroscopic abrasion arthroplasty, historical and pathologic perspective: present status. Arthroscopy 1986;2:54-69.

2. Steadman JR, Rodkey WG, Briggs KK, Rodrigo JJ. The microfracture technic in the management of complete cartilage defects in the knee joint. Orthopade 1999;28:26-32.

3. Bobic V. Arthroscopic osteochondral autograft transplantation in anterior cruciate ligament reconstruction: a preliminary clinical study. Knee Surg Sports Traumatol Arthrosc 1996;3:262-4.

4. Matsusue Y, Yamamuro T, Hama H. Arthroscopic multiple osteochondral transplantation to the chondral defect in the knee associated with anterior cruciate ligament disruption. Arthroscopy 1993;9:318-21. 
5. Outerbridge HK, Outerbridge AR, Outerbridge RE. The use of a lateral patellar autologous graft for the repair of a large osteochondral defect in the knee. J Bone Joint Surg [Am] 1995;77-A:65-72.

6. Yamashita F, Sakakida K, Suzu F, Takai S. The transplantation of an autogenic osteochondral fragment for osteochondritis dissecans of the knee. Clin Orthop 1985;201:43-50.

7. Bodo G, Hangody L, Szabo Z, et al. Arthroscopic autologous osteochondral mosaicplasty for the treatment of subchondral cystic lesion in the medial femoral condyle in a horse. Acta Vet Hung 2000;48:343-54.

8. Hangody L, Kish G, Karpati Z, Szerb I, Udvarhelyi I. Arthroscopic autogenous osteochondral mosaicplasty for the treatment of femoral condylar articular defects: a preliminary report. Knee Surg Sports Traumatol Arthrosc 1997;5:262-7.

9. Kish G, Modis L, Hangody L. Osteochondral mosaicplasty for the treatment of focal chondral and osteochondral lesions of the knee and talus in the athlete: rationale, indications, techniques, and results. Clin Sports Med 1999;18:45-66.

10. Brittberg M, Lindahl A, Nilsson A, et al. Treatment of deep cartilage defects in the knee with autologous chondrocyte transplantation. $N$ Engl J Med 1994;331:889-95.

11. Minas T. Chondrocyte implantation in the repair of chondral lesions of the knee: economics and quality of life. Am J Orthop 1998;27: 739-44.

12. Peterson L. Articular cartilage injuries treated with autologous chondrocyte transplantation in the human knee. Acta Orthop Belg 1996;62(Suppl I):196-200.

13. Peterson L, Minas T, Brittberg M, et al. Two- to 9-year outcome after autologous chondrocyte transplantation of the knee. Clin Orthop 2000;374:212-34.

14. Bugbee WD, Convery FR. Osteochondral allograft transplantation. Clin Sports Med 1999;18:67-75.

15. Garrett JC. Fresh osteochondral allografts for treatment of articular defects in osteochondritis dissecans of the lateral femoral condyle in adults. Clin Orthop 1994;303:33-7.

16. Ghazavi MT, Stockley I, Yee G, Davis A, Gross AE. Reconstruction of massive bone defects with allograft in revision total knee arthroplasty. $J$ Bone Joint Surg [Am] 1997;79-A:17-25.
17. Cao Y, Vacanti JP, Paige KT, Upton J, Vacanti CA. Transplantation of chondrocytes utilizing a polymer-cell construct to produce tissueengineered cartilage in the shape of a human ear. Plast Reconstr Surg 1997;100:297-302.

18. Vacanti CA, Langer R, Schloo B, Vacanti JP. Synthetic polymers seeded with chondrocytes provide a template for new cartilage formation. Plast Reconstr Surg 1991;88:753-9.

19. Bruder SP, Gazit D, Passi-Even L, Bab I, Caplan AI. Osteochondral differentation and the emergence of stage-specific osteogenic cell-surface molecules by bone marrow cells in diffusion chambers. Bone Miner Res 1990;11:141-51.

20. Zuk PA, Zhu M, Mizuno H, et al. Multilineage cells from human adipose tissue: implications for cell-based therapies. Tissue Eng 2001;7:211-28.

21. Krebs VE, Parker RD. Arthroscopic resection of an extrasynovial ossifying chondroma of the infrapatellar fat pad: end-stage Hoffa's disease? Arthroscopy 1994;10:301-4.

22. Ogilvie-Harris DJ, Giddens J. Hoffa's disease: arthroscopic resection of the infrapatellar fat pad. Arthroscopy 1994;10:184-7.

23. Lieberman JR, Le LQ, Wu L, et al. Regional gene therapy with a BMP-2 producing murine stromal cell line induces heterotopic and orthotopic bone formation in rodents. J Orthop Res 1998;16: 330-9.

24. Farndale RW, Buttle DJ, Barrett AJ. Improved quantitation and discrimination of suphated glycosaminoglycans by use of dimethylmethylene blue. Biochim Biophys Acta 1986;883:173-7.

25. Bruder SP, Jaiswal N, Haynesworth SE. Growth kinetics, selfrenewal, and the osteogenic potential of purified human mesenchymal stem cells during extensive subcultivation and following cryopreservation. J Cell Biochem 1997;64:278-94.

26. Carver SE, Heath CA. Increasing extracellular matrix production in regenerating cartilage with intermittent physiological pressure. Biotechnol Bioeng 1999;62:166-74.

27. Bloom, Fawcett, DW. A textbook of histology. 11th ed. Philadelphia, Pennsylvania; WB Saunders, 1986:188-97.

28. Wang EA, Israel DI, Kelly S, Luxenberg DP. Bone morphogenetic protein-2 causes commitment and differentiation in C3H10T1/2 and 3T3 cells. Growth Factors 1993;9:57-71. 